\title{
Ampicillin Sodium/Sulbactam Sodium
}

National Cancer Institute

\section{Source}

National Cancer Institute. Ampicillin Sodium/Sulbactam Sodium. NCI Thesaurus. Code C28823.

A combination formulation of the sodium salts of the antibiotic ampicillin and the betalactamase inhibitor sulbactam with antibacterial activity. Ampicillin, a broad-spectrum, semisynthetic penicillin, binds to and inactivates penicillin-binding proteins (PBP) located on the inner membrane of the bacterial cell wall, thereby interfering with the cross-linking of peptidoglycan chains necessary for bacterial cell wall strength and rigidity. As a result, the cell wall is weakened and the cell lyses. The sulbactam component irreversibly binds to bacterial beta-lactamase at or near its active site, thereby interfering with substrate binding and inhibiting bacterial metabolism of penicillin and cephalosporin beta-lactam antibiotics, effectively extending their antibiotic spectrum to include many beta-lactamresistant bacteria. 